\title{
A Survey on Diseases Detection and Classification of Agriculture Products using Image Processing and Machine Learning
}

\author{
Nilay Ganatra \\ Smt. Chandaben Mohanbhai Patel Institute of \\ Computer Applications \\ Charotar University of Science and Technology
}

(CHARUSAT)

\author{
Atul Patel, PhD \\ Smt. Chandaben Mohanbhai Patel Institute of \\ Computer Applications \\ Charotar University of Science and Technology
}

(CHARUSAT)

\begin{abstract}
Quality agriculture production is the essential trait for any nation's economic growth. So, recognition of the deleterious regions of plants can be considered as the solution for saving the reduction of crops and productivity. The past traditional approach for disease detection and classification requires enormous amount of time, extreme amount of work and continues farm monitoring. In the last few years, advancement in the technology and researchers' focus in this area makes it possible to obtain optimized solution for it. To identify and detect the disease on agriculture product various popular methods of the fields like machine learning, image processing and classification approaches have been utilized. This paper presents various existing techniques used to detect the disease of agriculture product. Also, paper surveys the mythologies utilized for disease detection, segmentation of the affected part and classification of the diseases. It also includes the summary of various feature extraction techniques, various segmentation techniques and various classifiers along with benefits and drawbacks.
\end{abstract}

\section{Keywords}

Classification, image processing, machine learning, segmentation, feature extraction, pre-processing

\section{INTRODUCTION}

In agriculture products, diseases are the main cause for the lessening in both quality and production of the agriculture products. So, plant disease diagnosis in early stage is very essential to cure and control them. Farmers puts their great effort in picking best seeds of plant and also provide proper environment for the growth of the plant, although there are lot of diseases that affects plant result in plant disease. In agriculture it is important to discover the plant diseases batches in the early stage which helps us to minimize the damage, reduce production costs, and rise the income. The human eye alone is not that much effective many a times to identify the correct disease. In past farmers used to follow naked eye observation of experts with samples of affected plants or expert used to visit the farm and based on their suggestions farmers were taking the corrective action to cure the plant diseases. In this method, it is very difficult to find trust worthy expert and the solution does not work properly for the large fields, the method takes long time. Also, this method is expensive because it requires continuous monitoring of experts. Agriculture is the root for the economy of any country and so the correct and timely identification of agriculture products diseases is very important. So, we need some automatic, fast, accurate and less expensive methods to detect diseases. Modern technological advancement in the field of image processing and machine learning will help farmers in the aspect of cost reduction of pesticides. Mainly there are two types of factors which cause the diseases in the agriculture products; living and nonliving agents. Insects, bacteria, fungi and viruses come under the category of living agents while temperature changes, excess moisture, insufficient light, less nutrients and pollution in air come under non-living agents. Agriculture related many applications are developed for leaf identification, lead diseases detection, fruit diseases etc. All these applications require digital images which are captured through digital camera. Then image processing and machine learning techniques are applied on captured images to extract necessary information for the analysis. In this paper we are presenting survey on different plant disease detection and classification techniques using image processing and machine learning which is used for fast, spontaneous, automatic and accurate detection as well as classification of plant leaf diseases. The various stages of disease detection and identification are image acquisition, image pre-processing, image segmentation, feature extraction and classification

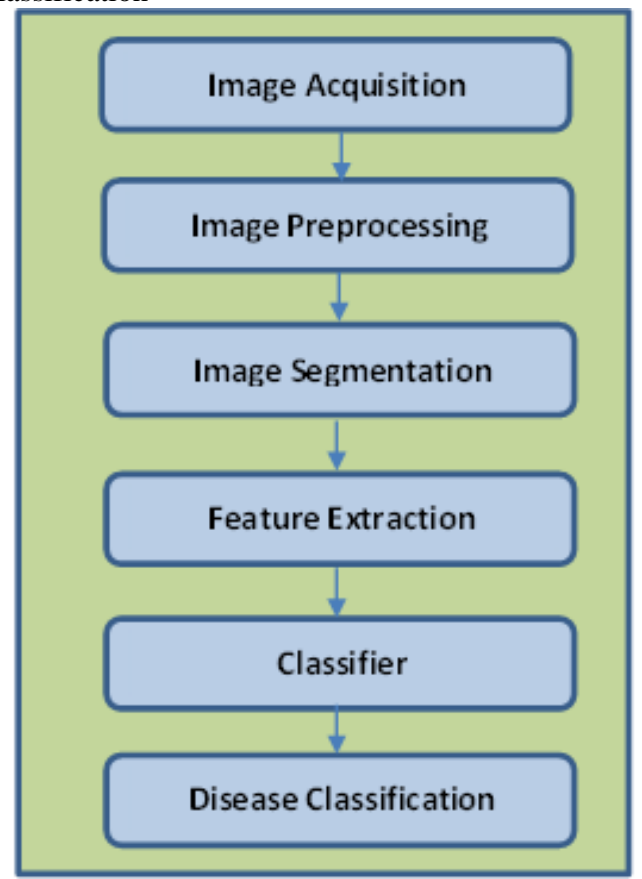

Figure 1. Steps to detect and classify disease from agriculture product. 


\section{RELATED WORK}

Ajay Gurjar \& et al (and other) [1]. In this paper three diseases (Red Spots, Leaf Crumple and White Spots) detection have been done using Eigen feature regularization and extraction technique. With the proposed algorithm they are able to achieve $90 \%$ accuracy in detection of Red Spot (Fungal Disease).

Yan-Cheng Zhang \& et al (and other) [2]. In this paper authors proposed fuzzy selection approach i.e. fuzzy curves (FC) and surfaces (FS) on cotton disease leaves image. They identify the best set of features using fuzzy feature selection approach. This research follows process in two steps. In the first step FC automatically isolate important and required features from the original feature set and eliminate the inaccurate features. Then in the second step by utilizing FS to obtain the feature dependent on the significant feature. This approach is particularly important to reduce the dimensionality of feature space which provides simplified practical implementation for classification applications.

Libo Liu \& et al (and other) [3]. In "Extraction of the Rice leaf disease image based on BP neural network" authors' proposed BP Neural network classifier for classifying health and diseased part of rice leaves. In research authors has selected brown spot as research object. They have taken sample images from the northern part of Ningxia Hui autonomous region. In this research coloured features of diseases and health portion passed as input for the BP neural network. This method is also used to identify the other diseases as shown in result.

Sachin D. Khirade \& et al (and other) [4]. In this paper authors highlighted various stages of disease detection like image acquisition, image pre-processing, image segmentation, feature extraction and classification. Moreover, they have discussed the different methods used for plant diseases detection using images of leaves. Moreover, this paper highlights some feature extraction and segmentation algorithms that can be used for plant disease detection.

Jitesh P Shah \& et al (and other) [5]. This paper concisely discusses the important methods of images processing and machine that can be applied to plant disease detection and classification. Survey of 19 papers covering the work on rice plant diseases and other different fruits and plants has been carried out by the authors based on important criteria like size of dataset, no. of classes (diseases), Segmentation and preprocessing techniques, classifiers and its accuracy etc.

Shiv Ram Dubey \& et al (and other) [6]. In this paper apple fruit diseases detection and classification solution has been proposed and practically validated. In the proposed solution $\mathrm{K}-\mathrm{Means}$ clustering technique is used for image segmentation, then feature extraction from the segmented image has been done and Multi-class Support Vector Machine is used for classification. The proposed solution provides accuracy up to 93\%.

Monika Jhuria, Ashwani Kumar \& et al [7]. In this paper using Image Processing authors monitor the diseases on the fruit right from the plantation to harvesting. Neural network with backpropagation used to train the system. Two diseases of apple and three of grapes are selected for the implementation. Classification and mapping of the images to the respective disease categories is done using colour, texture and morphology feature vectors. Out of these three feature vector, morphology gives $90 \%$ correct result over other two. Bhavini J. Samajpati \& et al (and other) [8]. In this paper authors mainly discussed about three diseases which cause major loss in yield and production of good quality apples. Apple scab is gray or brown spots on the apple. Apple rot is small dipped, black or brown which can be occurred by red halo. Apple blotch is fungal disease which appears on the apple surface and makes apple as dark, uneven and lobed edges. This paper survey various methodology utilized for apple disease detection, segmentation and classification using image processing. Also, summary of various texture analysis methods, segmentation techniques and various classifiers along with their pros and cons are discussed.

Godliver Owomugisha \& et al (and other) [9]. In this paper authors presents an application of machine learning for the crop disease diagnosis based on the image captured using smartphone. They have represented a classification system with 5 classes to determine the state of disease of a plant. Total 5 classes used to represent health class and 4 for diseases classes. Also, further classification has been done for severity levels of the 4 diseases. The assigned classes for severity are $1-5$, where 1 is for healthy plant and 5 is for diseased plant. Also, they have used different feature extraction methods and shows different extraction methods affects the performance of the classifiers. They took four major diseases affecting cassava plant. Farmer can upload the image by smart phone and obtain the disease score from the server.

A. Meunkaewjinda \& et al (and other) [10]. Authors of the paper mainly focus on the grape leaf disease diagnosis using multiple artificial intelligent techniques. In the proposed work is mainly divided into three parts: i) pre-processing using grape leaf colour segmentation ii) grape leaf disease segmentation and iii) analysis and classification of diseases. They have used self-organizing feature map together with a back-propagation neural network is used to recognize grape leaf image colour. Also, for segmentation self-organizing feature map with genetic algorithms for optimization is used and a support vector machine is used for classification. Moreover, Gabor wavelet filter is applied to segmented image for better analysis of diseases colour features. Finally, support vector machine is again applied to classify the grape leaf disease from the classes: scab disease, rust disease and no disease.

M. Ravindra Naik \& et al (and other) [11]. In this paper authors use SVM to identify whether the leaves are affected by diseases or not. The Genetic algorithm is used for image segmentation, which is crucial aspect for disease identification in agriculture products. And then if it is affected by any diseases than again NN classifier is used to classify the disease of the particular leaf. The proposed algorithm was tested and executed on Banana, beans, jackfruit, lemon, mango, potato, tomato, and sapota.

Suhaili Beeran Kutty \& et al (and other) [12]. This paper focuses on the classification of Anthracnose and Downey Mildew, leaf disease of watermelon using neural network analysis. Some of the infected leaf samples were collected using camera with specific calibration procedure under controlled environment. To classify the watermelon's leaf diseases, colour feature extraction from RGB colour model is used where from the identified Regions of Interest (ROI) the RGB pixel colour indices have been extracted. Prosed architecture used Statistical Package for the Social Sciences (SPSS) and Neural Network Pattern Recognition Toolbox in MATLAB.

K. Muthukannan \& et al (and other) [13]. In this paper various neural network algorithms are used to classify the detected spot diseases in the leaves to avoid extreme amount of 
pesticides for the plant disease treatment. In this paper methodology used to classify the diseased plant are Feed Forward Neural Network (FFNN), Learning Vector Quantization (LVQ) and Radial Basis Function Networks (RBF) by using various shape and texture features from the affected leaf image. The proposed algorithm in the paper is tested on the bean and bitter gourd leaves.

Loyce Selwyn Pinto \& et al (and other) [14]. In this paper to detect and classify sunflower crop disease image processing is used. After applying pre-processing on the captured images through the digital camera, the k-means clustering is used to get the diseased part of the leaf. Then various machine learning algorithms are applied on identified part and classified based on colour and texture features. Also, it compares accuracy between various machine learning algorithms like K-Nearest Neighbors, Multi-Class Support Vector Machine, Naive Bayes and Multinomial Logistic Regression to get high accuracy. The feature set consists of Contrast, Energy, Mean, Homogeneity, Standard Deviation and Coarseness.

\subsection{Image Segmentation Techniques}

The meaning of segmentation is to identify the region of interest from the image. The segmentation is basically used to make simpler and/or change the way of representation of an image into something which is easier and meaningful to analyse

[15]

Table 1: Summary of different segmentation techniques [16]

\begin{tabular}{|c|c|c|c|}
\hline Segmentation Technique & Description & Benefits & Drawbacks \\
\hline Thresholding Method & $\begin{array}{l}\text { It is the simplest method } \\
\text { approach of image } \\
\text { segmentation by dividing the } \\
\text { image pixels based on their } \\
\text { intensity level. The threshold } \\
\text { value can be computed } \\
\text { depending on the peak of the } \\
\text { image histogram. }\end{array}$ & $\begin{array}{l}\text { Any prior information about } \\
\text { image is not required } \\
\text { Fast, simple } \\
\text { computationally } \\
\text { inexpensive. } \\
\text { Can be easily applicable and } \\
\text { suitable for real life } \\
\text { applications }\end{array}$ & $\begin{array}{l}\text { It does not work well for } \\
\text { image with broad and flat } \\
\text { valleys and does not have any } \\
\text { peak. } \\
\text { Spatial information may be } \\
\text { ignored and resultant image } \\
\text { cannot guarantee that the } \\
\text { segmented regions are } \\
\text { contiguous. } \\
\text { Threshold selection is very } \\
\text { crucial. } \\
\text { Extremely noise sensitive. }\end{array}$ \\
\hline Region Based Method & $\begin{array}{l}\text { In this method construction } \\
\text { of segmentation region is } \\
\text { based on association and } \\
\text { dissociating neighbour pixels. } \\
\text { It works on the principle of } \\
\text { homogeneity, with the fact } \\
\text { the adjacent pixels inside } \\
\text { specific region flocks related } \\
\text { characteristics and unrelated } \\
\text { to the pixel in the other } \\
\text { region. }\end{array}$ & $\begin{array}{l}\text { It is flexible enough to } \\
\text { choose between interactive } \\
\text { and automatic technique for } \\
\text { image segmentation. } \\
\text { More clear object boundaries } \\
\text { by the flow from the inner } \\
\text { point to outer region. } \\
\text { Gives more accurate result } \\
\text { compare to other methods. }\end{array}$ & $\begin{array}{l}\text { Required more computation } \\
\text { time and memory and } \\
\text { sequential in nature. } \\
\text { Noisy seed selection by user } \\
\text { leads to faulty segmentation. } \\
\text { Because of splitting scheme in } \\
\text { region splitting segments } \\
\text { seem square. }\end{array}$ \\
\hline Clustering Method & $\begin{array}{l}\text { In this method pixels having } \\
\text { similar characteristics in } \\
\text { image are segmented into } \\
\text { same clusters. Cluster an } \\
\text { image into different parts } \\
\text { based on the features of the } \\
\text { image. The k-means } \\
\text { algorithm is commonly used } \\
\text { for this method. }\end{array}$ & $\begin{array}{l}\text { Homogeneous regions can } \\
\text { be easily obtained. } \\
\text { Computationally faster. } \\
\text { K-means works faster for the } \\
\text { smaller value of K. }\end{array}$ & $\begin{array}{l}\text { Poor worst-case behaviour. } \\
\text { It requires similar size } \\
\text { clusters, so the assignment of } \\
\text { the adjacent cluster center is } \\
\text { the correct assignment. }\end{array}$ \\
\hline Edge Based Method & $\begin{array}{l}\text { In this method all edges are } \\
\text { detected first and then to } \\
\text { segment the required region, } \\
\text { edges are connected to form } \\
\text { the object boundaries. It is } \\
\text { based on discontinuity } \\
\text { detection in edges. }\end{array}$ & $\begin{array}{l}\text { Works well for the images } \\
\text { with better contrast between } \\
\text { regions. }\end{array}$ & $\begin{array}{l}\text { Work not well for the image } \\
\text { having more edges. } \\
\text { Selection of right object edge } \\
\text { is difficult. }\end{array}$ \\
\hline $\begin{array}{l}\text { Partial Differential Equation } \\
\text { Based Segmentation Method }\end{array}$ & $\begin{array}{l}\text { These are fast and } \\
\text { appropriate for time critical } \\
\text { applications. It is based on } \\
\text { the differential equation } \\
\text { working. }\end{array}$ & Fastest Method & $\begin{array}{l}\text { Computational Complexity is } \\
\text { more }\end{array}$ \\
\hline
\end{tabular}




\subsection{Feature Extraction}

When input data to an algorithm is very large and it is supposed to be redundant, than it can be transferred into small set of features. Finding the subset of the initial features is called feature selection. It is expected that selected features contains the required information, so the preferred task can be performed with using reduced representation [17].

Table 2: Summary of different colour techniques

\begin{tabular}{|c|c|c|c|}
\hline Method & Description & Merits & Demerits \\
\hline L*a*b [18] & $\begin{array}{l}\text { a) This colour space consists one } \\
\text { channel for Luminance and two } \\
\text { other channels are a and b known as } \\
\text { chromaticity layers. } \\
\text { b) Space consists of dimension } \mathrm{L} \\
\text { for lightness and a and b for colour } \\
\text { adversary dimensions. }\end{array}$ & $\begin{array}{l}\text { a) In this colour and intensity } \\
\text { manage individually. } \\
\text { b) It can measure small colour } \\
\text { differences. }\end{array}$ & $\begin{array}{ll}\text { a) Problem of } & \text { singularity } \\
\text { as other } & \text { nonlinear } \\
\text { transformation. } & \end{array}$ \\
\hline HSV Histogram [19] & $\begin{array}{l}\text { a) HSV can be represented as } \\
\text { hexacone in three dimensions in } \\
\text { which intensity can be represented } \\
\text { as central vertical axis. } \\
\text { b) It is Hue, saturation value. } \\
\text { c) Colours are described in term of } \\
\text { shades and brightness }\end{array}$ & $\begin{array}{l}\text { a) Accuracy is more } \\
\text { b) Applicable for real time } \\
\text { applications. }\end{array}$ & $\begin{array}{l}\text { a) Sensitivity to lighting } \\
\text { variations is less. }\end{array}$ \\
\hline RGB [18] & $\begin{array}{l}\text { a) It is colour space based on RGB } \\
\text { model. } \\
\text { b) Consists of three independent } \\
\text { image planes, one for each primary } \\
\text { colour red, green and blue } \\
\text { c) It is an additive model }\end{array}$ & a) suitable for display & $\begin{array}{l}\text { a) It is highly correlative. } \\
\text { So, not good for colour } \\
\text { image processing }\end{array}$ \\
\hline YUV [18] & $\begin{array}{l}\text { a) Main channel luminance } \\
\text { describes the light intensity like rod } \\
\text { cells of the retina } \\
\text { b) Chrominance components } U \text { and } \\
\text { V carry the colour information } \\
\text { c) In this black and white colour } \\
\text { information is separated from the } \\
\text { colour information }\end{array}$ & $\begin{array}{l}\text { a) Overcome the correlation } \\
\text { of RGB to some extent and } \\
\text { require less computation time }\end{array}$ & $\begin{array}{l}\text { a) Correlation exists but } \\
\text { less than RGB }\end{array}$ \\
\hline
\end{tabular}

Table 3: Summary of different texture feature extraction techniques [18]

\begin{tabular}{|c|c|c|c|}
\hline Method & Description & Merits & Demerits \\
\hline $\begin{array}{c}\text { Grey Level Co-occurrence } \\
\text { Matrices }\end{array}$ & $\begin{array}{l}\text { a) It is statistical method used } \\
\text { to examine the texture which } \\
\text { considers the spatial } \\
\text { relationship of pixels is the } \\
\text { grey level co-occurrences } \\
\text { matrix. }\end{array}$ & $\begin{array}{l}\text { a) Feature vector length is } \\
\text { small } \\
\text { b) Can be applied for the } \\
\text { different colour space for } \\
\text { colour co-occurrence matrix }\end{array}$ & $\begin{array}{l}\text { a) Many matrices is required } \\
\text { to be computed } \\
\text { b) It's not invariant with } \\
\text { rotation and scaling }\end{array}$ \\
\hline $\begin{array}{l}\text { Wavelets } \\
\text { Transform }\end{array}$ & $\begin{array}{l}\text { a) It works better on the } \\
\text { frequency domain rather than } \\
\text { the spatial domain }\end{array}$ & $\begin{array}{l}\text { a) Best features with the } \\
\text { higher accuracy can be } \\
\text { produced }\end{array}$ & $\begin{array}{l}\text { a) It is quite complex and } \\
\text { slower }\end{array}$ \\
\hline $\begin{array}{c}\text { Independent Component } \\
\text { Analysis }\end{array}$ & $\begin{array}{l}\text { a) It is computational method } \\
\text { for splitting a multivariate } \\
\text { signal into additive small } \\
\text { subcomponents }\end{array}$ & $\begin{array}{l}\text { a) Higher order statistics can } \\
\text { be easily obtained } \\
\text { b) It separates mixed signal } \\
\text { into a set of independent } \\
\text { signals. }\end{array}$ & a) It is rarely used method. \\
\hline Gabor filter & $\begin{array}{l}\text { a) It is used to analyse } \\
\text { specific frequency content in } \\
\text { the image in specific } \\
\text { directions in a localized } \\
\text { region around the region of } \\
\text { interest }\end{array}$ & $\begin{array}{l}\text { a) It is multi resolution and } \\
\text { multi-scale filter } \\
\text { b) It is used for orientation, } \\
\text { spectral bandwidth } \\
\text { and spatial extent }\end{array}$ & $\begin{array}{l}\text { a) So many filters are used in } \\
\text { application so overall } \\
\text { computational cost is high. }\end{array}$ \\
\hline
\end{tabular}




\subsection{Classifiers}

Classifiers are used to classify the images according to their features. There are various classifiers like Naive Bayes
Classifier, k-Nearest Neighbors (k-NN), Support Vector Machine (SVM), Artificial Neural Network (ANN) and Random Forest Tree Classifier.

Table 4: Summary of different classifiers [18]

\begin{tabular}{|c|c|c|c|}
\hline Classifier & Description & Merits & Demerits \\
\hline Naive Bayes Classifier & $\begin{array}{l}\text { a) It is Probabilistic } \\
\text { classifier } \\
\text { b) Strong independence } \\
\text { assumption theorem } \\
\text { c) value of the particular } \\
\text { feature is independent of the } \\
\text { value of any other feature }\end{array}$ & $\begin{array}{l}\text { a)Small amount of training } \\
\text { data is required for } \\
\text { classification }\end{array}$ & $\begin{array}{l}\text { a)Interaction between } \\
\text { features can't be learnt } \\
\text { because of independency } \\
\text { among the feature }\end{array}$ \\
\hline K-nearest neighbour & $\begin{array}{l}\text { a) It is statistical and non- } \\
\text { parametric classifier } \\
\text { b) Weight can be assigned to } \\
\text { the contributions of the } \\
\text { neighbours, so nearer } \\
\text { neighbour donate more in } \\
\text { the average than the distance } \\
\text { neighbour } \\
\text { c) Distance metric has been } \\
\text { calculated for samples and } \\
\text { classify based on this } \\
\text { distance } \\
\text { d) It uses Euclidean distance } \\
\text { to calculate distance }\end{array}$ & $\begin{array}{l}\text { a) Implementation is simple } \\
\text { b) Don't required classes to } \\
\text { be linearly separable }\end{array}$ & $\begin{array}{l}\text { a) Very Sensitive to noisy or } \\
\text { irrelevant data } \\
\text { b) More time consuming } \\
\text { testing process because } \\
\text { requires calculation of } \\
\text { distance to all known } \\
\text { instances }\end{array}$ \\
\hline Support Vector Machine & $\begin{array}{l}\text { a) It is based on the decision } \\
\text { planes that define decision } \\
\text { boundaries. } \\
\text { b) There are two stages of its } \\
\text { working } \\
\text { 1) off-line process } \\
\text { 2) online process } \\
\text { c) Multi-class support vector } \\
\text { machine as a set of binary } \\
\text { vector machine is used for } \\
\text { training and classification }\end{array}$ & $\begin{array}{l}\text { a) It is effective in high } \\
\text { dimensional spaces } \\
\text { b) In comparison with other } \\
\text { classification techniques } \\
\text { classification accuracy is } \\
\text { high. } \\
\text { c) SVM is robust enough, } \\
\text { even though training } \\
\text { samples have some } \\
\text { distortion. }\end{array}$ & $\begin{array}{l}\text { a) Training time is very high } \\
\text { with large data set } \\
\text { b) For mapping original data } \\
\text { into high dimension data } \\
\text { selection of kernel function } \\
\text { and kernel parameters is } \\
\text { difficult }\end{array}$ \\
\hline Decision Tree & $\begin{array}{l}\text { a) It repetitively divides the } \\
\text { working area into small sub } \\
\text { parts by identifying its } \\
\text { attributes. } \\
\text { b) Leaves present the class } \\
\text { labels and branches present } \\
\text { features that lead to those } \\
\text { classes. }\end{array}$ & $\begin{array}{l}\text { a) Small sized trees can be } \\
\text { easily interpreted } \\
\text { b) For many simple data sets } \\
\text { accuracy is comparable with } \\
\text { other classifications }\end{array}$ & $\begin{array}{l}\text { a) For some datasets it is } \\
\text { observed to over fit with } \\
\text { noisy classification tasks. }\end{array}$ \\
\hline Artificial Neural Network & $\begin{array}{l}\text { a) It is derived from the } \\
\text { concept of the human } \\
\text { biological neurons system } \\
\text { b) It consist of two datasets } \\
\text { one for training and one for } \\
\text { testing }\end{array}$ & $\begin{array}{l}\text { a) It is robust and can handle } \\
\text { noisy data } \\
\text { b) Well suited to analyse } \\
\text { complex numbers }\end{array}$ & $\begin{array}{l}\text { a) Requires more training } \\
\text { time } \\
\text { b) Requires large training } \\
\text { samples } \\
\text { c) Requires more processing } \\
\text { time }\end{array}$ \\
\hline
\end{tabular}

\section{CONCLUSION}

In this paper we have presented survey on different agriculture product diseases detection and classification using various image processing and machine learning techniques. We have highlighted summary of different colour and texture based feature extraction with their advantages and disadvantages. Moreover, we have discussed different segmentation techniques with its benefits and negative marks. Also, summary of different segmentation techniques along with its merits and disadvantages discussed briefly in the paper. In future we are going to use some of the methods discussed in this paper for our research work.

\section{REFERENCES}

[1] V. A. G. Ajay a. Gurjar, "disease detection on cotton leaves by eigenfeature regularization and extraction technique," internation journal of electronics, communication \& soft computing science and engineering(ijecscse), vol. I, no. I.

[2] H.-p. M. B. H. M.-x. L. Yan-cheng zhang, "features selection of cotton disease leaves image based on fuzzy feature selection techniques," in ieee proceedings of the 
2007 international conference on wavelet analysis and pattern recognition, beijing, china, 2007.

[3] G. Z. Libo liu, "extraction of the rice leaf disease image based on bp neural network," in ieee, 2009.

[4] P. Sachin d. Khirade, "plant disease detection using image processing," in ieee 2015 international conference on computing communication control and automation, pune, 2015.

[5] H. B. P. V. K. D. Jitesh p. Shah, "a survey on detection and classification of rice plant diseases," in ieee international conference on current trends in advanced computing (icctac), bangalore, 2016.

[6] S. J. Shiv ram dubey, "detection and classification of apple fruit diseases using complete local binary patterns," in ieee 2012 third international conference on computer and communication technology, 2012.

[7] K. B. Monika jhuria, "image processing for smart farming: detection of disease and fruit grading," in proceedings of the 2013 ieee second international conference on image information processing , 2013.

[8] S. D. D. Bhavini j. Samajpati, "a survey on apple fruit diseases detection and classification," international journal of computer applications, vol. 130, no. 13, pp. 25-32, november 2015.

[9] E. M. Godliver owomugisha, "machine learning for plant disease incidence and severity measurements from leaf images," in 15th ieee international conference on machine learning and applications, 2015.

[10] P. K. K. A. A. Meunkaewjinda, "grape leaf disease detection from color imagery using hybrid intelligent system," in ieee 2008 5th international conference on electrical engineering/electronics, computer, telecommunications and information technology, 2008.

[11] M. R. S. M. Ravindra naik, "plant leaf and disease detection by using hsv features and svm classifier," international journal of engineering science and computing, vol. 6, no. 12, pp. 3794-3797, 2016.

[12] N. E. A. H. H. Suhaili beeran kutty, "classification of watermelon leaf diseases using neural network analysis," ieee business engineering and industrial applications colloquium, 2013.

[13] P. L. R. P. S. P. N. K. Muthukannan, "classification of diseased plant leaves using neural network algorithms," arpn journal of engineering and applied sciences, vol. 10 , no. 4,2015

[14] R. M. U. R. Loyce selwyn pinto, "crop disease classification using texture analysis," in ieee international conference on recent trends in electronics information communication technology, 2016.

[15] F. Encyclopedia, “image segmentation," [online]. Available: https://en.wikipedia.org/wiki/image_segmentation.

[16] X. J. Y. S. J. W. H.d. Cheng, "color image segmentation: advances and prospects," elsevier, 2001.

[17] T. F. E. Wikipedia, "feature extraction," [online]. Available: https://en.wikipedia.org/wiki/feature_extraction.

[18] U. K. J. D. G. T. Uravashi solanki, "a survey on detection of disease and fruit grading," international journal of innovative and emerging, vol. 2, no. 2, 2015.

[19] V. L. M.-f. D. O. Kleynen, “development of a multispectral vision system for the detection of defects on apples," elsevier, 2004. 